\title{
Adenoviral Delivery of E2F-1 Directs Cell Cycle Reentry and p53-independent Apoptosis in Postmitotic Adult Myocardium In Vivo
}

\author{
Ramtin Agah, ${ }^{\star \ddagger}$ Lorrie A. Kirshenbaum, ${ }^{\star \star}$ Maha Abdellatif, ${ }^{\star \ddagger}$ Luan D. Truong, \\ and Michael D. Schneider ${ }^{\star} \$ \uparrow$

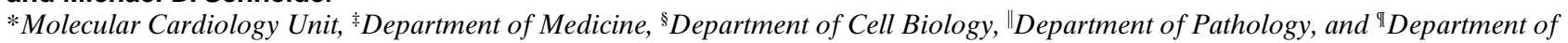 \\ Molecular Physiology and Biophysics, Baylor College of Medicine, Houston, Texas 77030; and **Institute of Cardiovascular Sciences, \\ St. Boniface General Hospital Research Centre, Department of Physiology, Faculty of Medicine, University of Manitoba, Winnipeg, \\ Manitoba R2H2A6, Canada
}

\begin{abstract}
Irreversible exit from the cell cycle precludes the ability of cardiac muscle cells to increase cell number after infarction. Using adenoviral E1A, we previously demonstrated dual pocket protein- and $\mathrm{p300}$-dependent pathways in neonatal rat cardiac myocytes, and have proven that E2F-1, which occupies the $\mathrm{Rb}$ pocket, suffices for these actions of E1A. By contrast, the susceptibility of adult ventricular cells to viral delivery of exogenous cell cycle regulators has not been tested, in vitro or in vivo. In cultured adult ventricular myocytes, adenoviral gene transfer of E2F-1 induced expression of proliferating cell nuclear antigen, cyclin-dependent protein kinase 4, cell division cycle 2 kinase, DNA synthesis, and apoptosis. In vivo, adenoviral delivery of E2F-1 by direct injection into myocardium induced DNA synthesis, shown by 5 '-bromodeoxyuridine incorporation, and accumulation in G2/M, by image analysis of Feulgen-stained nuclei. In $\mathrm{p}^{-1-}$ mice, the prevalence of G1 exit was more than twofold greater; however, E2F-1 evoked apoptosis and rapid mortality comparably in both backgrounds. Thus, the differential effects of E2F-1 on G1 exit in wild-type versus p53-deficient mice illustrate the combinatorial power of viral gene delivery to genetically defined recipients: E2F-1 can override the G1/S checkpoint in postmitotic ventricular myocytes in vitro and in vivo, but leads to apoptosis even in p53 ${ }^{-1-}$ mice. (J. Clin. Invest. 1997. 100:2722-2728.) Key words: adenovirus $\bullet$ cardiac muscle $\bullet$ cell cycle $\bullet$ E2F-1 • p53
\end{abstract}

\section{Introduction}

Biological control of the cell cycle entails a series of checkpoints regulated by cyclin-dependent protein kinases $(\mathrm{Cdks})^{1}$ and their obligatory activating partners, the cyclins $(1,2)$. Cdk activity governs, first, a restriction point at the G1/S boundary, via pocket protein phosphorylation and resulting release of

R. Agah and L.A. Kirshenbaum contributed equally to this work. Address correspondence to Dr. Michael D. Schneider, Molecular Cardiology Unit, One Baylor Plaza, Room 506C, Baylor College of Medicine, Houston, TX 77030. Phone: 713-798-6683; FAX: 713-7987437; E-mail: michaels@bcm.tmc.edu

Received for publication 27 June 1997 and accepted in revised form 1 October 1997.

J. Clin. Invest.

(C) The American Society for Clinical Investigation, Inc. 0021-9738/97/12/2722/07 \$2.00

Volume 100, Number 11, December 1997, 2722-2728

http://www.jci.org
E2F transcription factors required for DNA synthesis (3). Blocking E2F-1 function with a Cdk inhibitor (4), nonphosphorylatable pocket proteins (5), or E2F sites as a transcription factor decoy (6) has been applied successfully in vivo to inhibit proliferation in the vessel wall, where pathology is associated with excess growth. A reciprocal strategy would attempt to reinduce proliferation in settings where growth may have therapeutic benefit, e.g., to restore cardiac myocyte number after myocardial infarction, as a conceptual alternative to cell transplantation (7).

We demonstrated previously a pocket protein-dependent pathway for growth arrest in neonatal cardiac myocytes, using adenoviruses to deliver the adenoviral protein E1A (8); like SV40 large T antigen (TAg), E1A binds Rb, displacing E2F (9). All actions of E1A in neonatal cardiac myocytes were reproduced by E2F-1 (10). Hence, cell cycle reentry was not contingent on associated properties of E1A. However, these results do not address the potential capability of E2F-1 to provoke terminally differentiated, adult cardiac myocytes to resume cycling de novo, a prerequisite for eventual clinical potential, and a fundamental issue for the biology of postmitotic cells (see reference 11).

Here, we used adenoviral delivery of E2F-1 to test whether forced expression of E2F-1 could provoke G1 exit even in postmitotic adult ventricular myocytes, and, second, whether adult ventricular myocardium likewise would be responsive to E2F-1 in vivo. A foreseeable obstacle to this approach in cardiac myocytes $(8,10)$ is that, as in other cell types, E2F-1 can not only provoke G1 exit but also apoptosis, which may be dependent largely on the tumor suppressor, p53 (12). This mechanism is viewed as a further control against inappropriate cell cycle entry in normally quiescent cells. Thus, although technically less straightforward than larger mammals, use of the mouse for cardiac injections would confer an opportunity for synergy between viral gene delivery and genetically engineered recipients. Therefore, we compared wild-type mice with mice lacking p53 (13) to test whether disruption of this gene facilitates cell cycle traversal induced by E2F-1, alleviating p53-dependent effects on checkpoints, apoptosis, or both in the adult heart.

\section{Methods}

Adenoviruses. Adenoviruses were propagated, purified, and titered as described (8). Adenovirus encoding human E2F-1, driven by the

1. Abbreviations used in this paper: BrdU, 5'-bromodeoxyuridine; $\mathrm{Cdc} 2$, cell division cycle 2 kinase; Cdk, cyclin-dependent protein kinase; CMV, cytomegalovirus; PCNA, proliferating cell nuclear antigen; PFU, plaque-forming units; TAg, SV40 large T antigen; TUNEL, terminal transferase-mediated dUTP-biotin nick end-labeling. 
cytomegalovirus (CMV) immediate-early promoter, was provided by J. Nevins (12). Adenovirus containing CMV-driven human Bcl-2 was provided by G. Chinnadurai (14). Control adenoviruses containing the CMV immediate-early promoter alone (15) and CMV-driven Escherichia coli $\beta$-galactosidase, modified by a nuclear localization signal (nls-LacZ) (8), were described previously.

Cell culture and adenovirus infection in vitro. Adult ventricular myocytes were isolated from 250-300-g male Sprague-Dawley rats and cultured in serum-free medium 199 (16). For epifluorescence microscopy, ventricular myocytes were transferred to glass coverslips coated with $20 \mu \mathrm{g} / \mathrm{ml}$ laminin (T. Borg, University of South Carolina); for Western blot studies, laminin-treated $35-\mathrm{mm}$ plastic dishes were used. Cells were infected with recombinant adenoviruses $\sim 40 \mathrm{~h}$ after plating, and analyzed 24-72 h after infection. Myocytes received each test virus at a concentration of 100 plaque-forming units (PFU)/cell, which achieves gene delivery to $\geq 80 \%$ of adult ventricular cells (16). To avoid factitious differences between groups resulting from virus itself or promoter competition, all cultures received a total of $200 \mathrm{PFU} /$ cell, keeping the dosage constant using the empty adenovirus described above, which contains the CMV transcriptional control region but no cDNA. DNA synthesis was monitored as the incorporation of 5'-bromodeoxyuridine (BrdU), added 54-72 h after infection, using fluorescein-conjugated mouse antibody $\mathrm{IgG}_{1}$ against $\mathrm{BrdU}$ (Boehringer Mannheim Biochemicals, Indianapolis, IN) $(8,10)$. Cardiac myocytes were labeled using MF20 antibody to sarcomeric myosin heavy chains (American Type Culture Collection, Rockville, MD) and rhodamine-conjugated sheep anti-mouse IgG. To visualize nuclear fragmentation induced by E2F-1, myocytes were stained with Hoechst dye 33258 for nuclear DNA. Apoptosis was assessed using the terminal transferase-mediated dUTP-biotin nick end-labeling (TUNEL) assay (10). The prevalence of apoptosis and BrdU-positive nuclei was determined for a total of at least 200 cells for each condition shown, in 6-12 replicate cultures, comprising two to four independent myocyte preparations.

Western blot analysis. Cell lysates $(25 \mu \mathrm{g} / \mathrm{lane})$ were resolved by SDS-PAGE and transferred electrophoretically to nitrocellulose. For detection of E2F-1, the filter was incubated for $1 \mathrm{~h}$ with mouse $\operatorname{IgG}_{2 \mathrm{a}}$ against human E2F-1 (KH95, $1 \mu \mathrm{g} / \mathrm{ml}$; Santa Cruz Biotechnology Inc., Santa Cruz, CA). For proliferating cell nuclear antigen (PCNA), the filter was incubated overnight with mouse $\operatorname{IgG}_{2 \mathrm{a}}$ against human PCNA (PC10, $1 \mu \mathrm{g} / \mathrm{ml}$; Santa Cruz Biotechnology Inc.). For cell division cycle 2 kinase (Cdc2), the filter was incubated overnight with rabbit antibody against human Cdc2 (C-19, $1 \mu \mathrm{g} / \mathrm{ml}$; Santa Cruz Biotechnology Inc.). Secondary antibodies were $0.5 \mu \mathrm{g} / \mathrm{ml}$ of horseradish peroxidase-conjugated sheep antibody against mouse IgG (Amersham Corp., Arlington Heights, IL) for E2F-1 and PCNA, and $0.5 \mu \mathrm{g} / \mathrm{ml}$ donkey anti-sheep IgG for Cdc2 (Amersham Corp.). Bound antibody was detected as chemiluminescence using ECL reagents (Amersham Corp.).

In vivo injection. 8-wk-old wild-type and $\mathrm{p} 53^{-1-}$ strain 129 mice (13) were subjected to apical intramyocardial injection under direct visualization after thoracotomy (15); these conditions result in gene delivery to $\sim 40 \%$ of ventricular myocytes in the cardiac apex (15). Wildtype mice were inoculated with $10^{10} \mathrm{PFU}$ of recombinant adenovirus containing CMV-driven E2F-1 $(n=7), \mathrm{CMV}$-driven nls-LacZ $(n=$ $4)$, or the CMV immediate-early promoter with no cDNA $(n=2)$; p53 ${ }^{-1-}$ mice were injected with CMV-driven E2F-1 $(n=4)$ or CMVdriven nls-LacZ $(n=2)$.

Histology. Mice were analyzed 2-7 d after injection. For measurements of DNA synthesis, mice were inoculated every $12 \mathrm{~h}$ by intraperitoneal injection with $1 \mathrm{ml}$ of $10 \mathrm{mM} \mathrm{BrdU}$. Hearts were bisected, mounted in freezing medium, and frozen in liquid nitrogen. Cryostat sections $(4-6 \mu \mathrm{m})$ were obtained using a coronal plane of section, and were fixed in $4 \%$ formaldehyde for $10 \mathrm{~min}$. For E2F immunocytochemistry, sections were incubated with $0.3 \% \mathrm{H}_{2} \mathrm{O}_{2}$ in methanol to inactivate endogenous peroxidase, then with rabbit antibody to E2F-1 (Santa Cruz Biotechnology Inc.), biotinylated goat antibody against rabbit IgG, and avidin-conjugated horseradish peroxi- dase (Santa Cruz Biotechnology Inc.). BrdU incorporation was detected using horseradish peroxidase-conjugated mouse antibody against BrdU (Boehringer Mannheim Biochemicals). Sections were incubated in diaminobenzidine $/ 10 \%$ hydrogen peroxide for $10 \mathrm{~min}$ and counterstained with eosin.

Quantitative image analysis of Feulgen-stained nuclei was performed as described (10). Only morphologically intact nuclei were scored. Normal rat liver was the internal control for calibration of DNA content. For BrdU cytophotometry and TUNEL analysis, $\sim 100$ cardiac nuclei were examined from each of two to three independent injections for each determination. Results were compared by ANOVA and the $\chi^{2}$ test, using a significance level of $P<0.05$.

\section{Results}

As a prelude to establishing the potential impact of E2F-1 on adult ventricular myocytes in vivo, postmitotic adult rat ventricular myocytes were studied in vitro, using serum-free medium to prevent the confounding effects of dedifferentiation over the time course of the experiment $(17,18)$. Adenovirus encoding E2F-1 evoked DNA synthesis in 19\% of adult rat ventricular myocytes $72 \mathrm{~h}$ after infection, vs. $0 \%$ of cells infected with the control virus $\left(\chi^{2}=72.5 ; P<0.0001\right.$; Fig. $1, M$ and $N)$; DNA synthesis was not detected at earlier time points. Sustained exposure to BrdU was chosen $(18 \mathrm{~h})$, given the need to detect a potentially infrequent response and the unknown kinetics for DNA synthesis in this terminally differentiated, postmitotic preparation. Because the prevalence for G1 exit was only $19 \%$, even with the protocol used here, no further attempt was made to estimate $\mathrm{S}$ phase with a briefer pulse of BrdU. G1 exit was accompanied by the induction of PCNA and the mitotic $\mathrm{Cdk}, \mathrm{Cdc} 2$, which were assayed as two representative E2F-dependent genes (19) (Fig. $1 R$ ). Thus, E2F-1 provokes $\mathrm{G} 1$ exit in postmitotic ventricular myocytes, as measured not only by DNA synthesis, but also by the expression of these endogenous cell cycle regulators. $\mathrm{Cdk} 4$ was also induced, indicating that exogenous E2F-1 can reverse the downregulation of Cdk4 that ordinarily occurs in adult myocardium (20, 21). However, no increase in cell number was seen, and mitotic figures were not detected even in adult ventricular myocytes receiving E2F-1 + Bcl-2.

As observed previously in neonatal ventricular myocytes (10), G1 exit triggered by E2F-1 was accompanied by apoptosis: $39 \%$ were positive for the TUNEL reaction, vs. $1.2 \%$ of adult ventricular myocytes infected with the control virus $\left(\chi^{2}=\right.$ 21.9, $P<0.0001$; Fig. $1, I$ and $J)$. Apoptosis was alleviated by coinfection with Bcl-2 $\left(17 \% ; \chi^{2}=26.2, P<0.0001\right.$, vs. E2F-1 alone; Fig. $1 L$ ), and this was accompanied by a further, reciprocal increase in BrdU-positive cells $\left(47 \% ; \chi^{2}=19.2, P=\right.$ 0.0001 , vs. E2F-1 alone; Fig. $1 P$ ). The combined proportion of BrdU- and TUNEL-positive nuclei was comparable in cells receiving E2F-1 versus E2F-1 + Bcl-2. Bcl-2 by itself did not induce DNA synthesis (Fig. $1 O$ ). The prevalence of apoptosis and BrdU-positive nuclei was determined in at least six cultures and a total of at least 200 cells, for each condition shown, and was similar in each of these replicate studies. Similar results were seen using Hoechst dye 33258 to assess nuclear fragmentation (Fig. 1, $A-D$ ). In other cell types, Bcl-2 is known not to override the $\mathrm{G} 2 / \mathrm{M}$ checkpoint $(22,23)$. Thus, the results are more consistent with the relative rates of G1 exit, or merely the rescue of cycling E2F-infected cells, when exogenous Bcl-2 is provided, than with the theoretical possibility that $\mathrm{Bcl}-2$ 

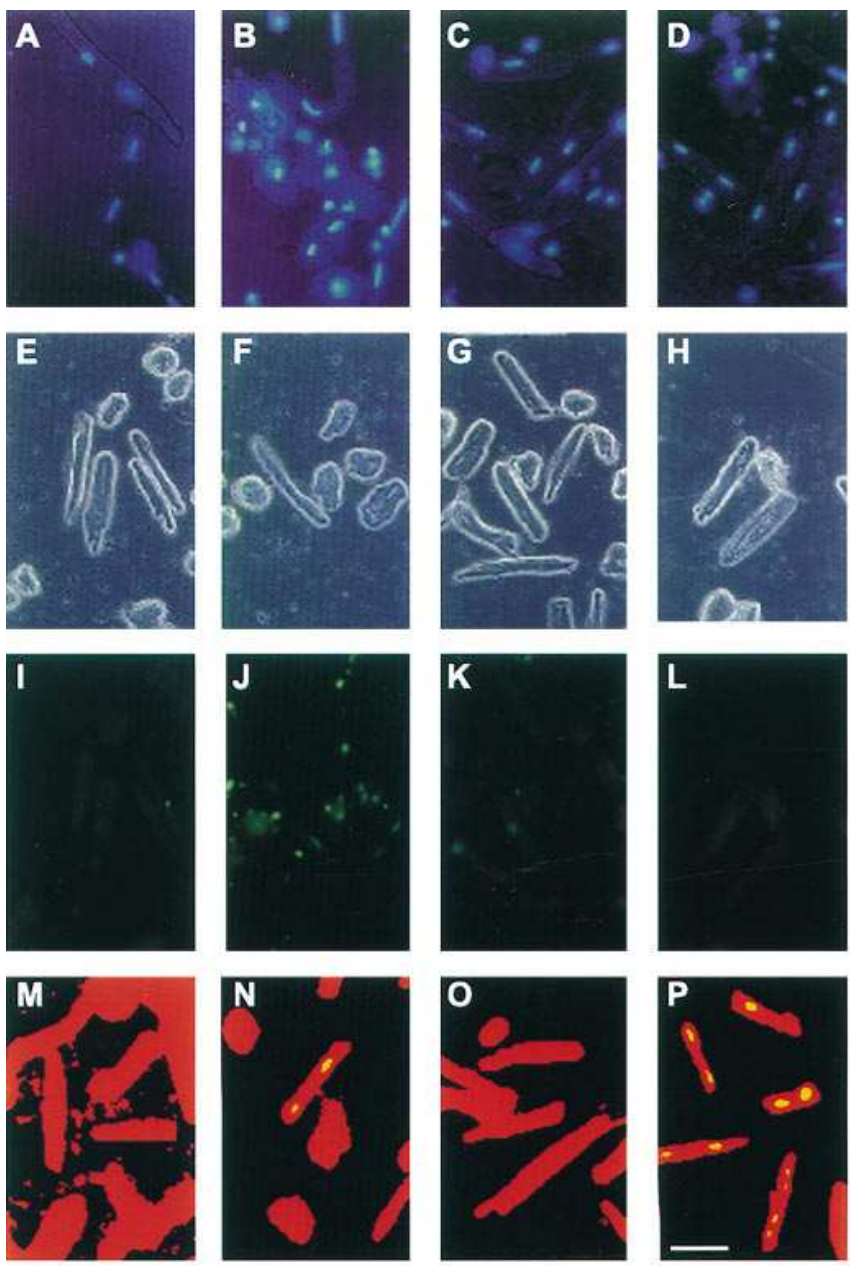

control

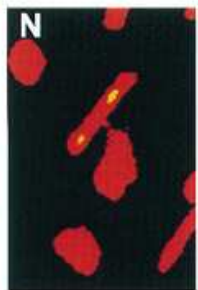

E2F-1

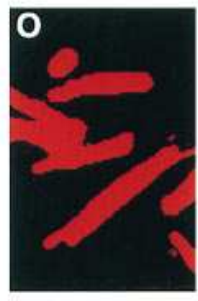

Bcl-2

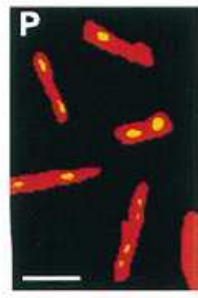

E2F-1

$+\mathrm{Bcl}-2$

Q
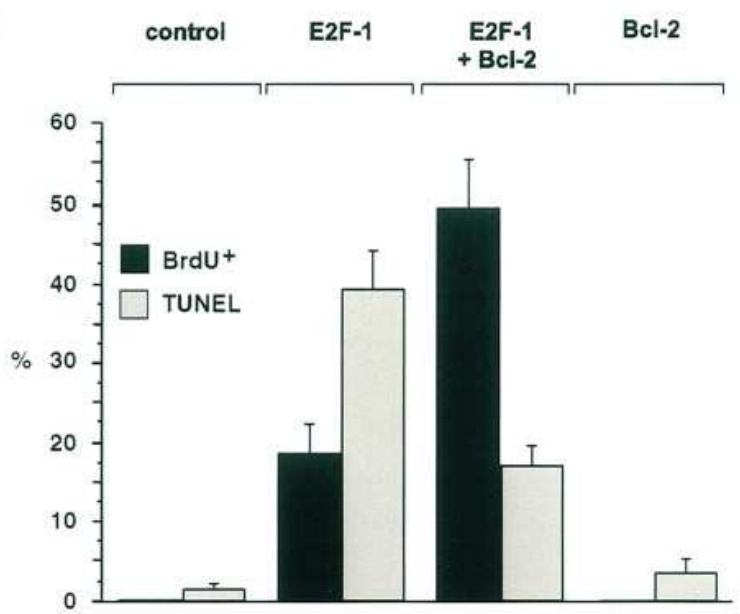

$\mathbf{R}$
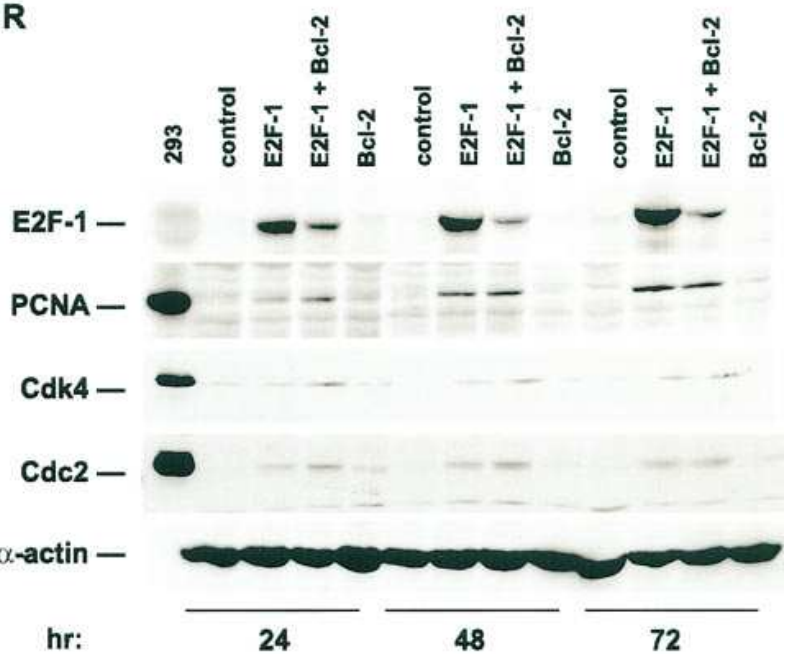

Figure 1. E2F-1 provokes S phase reentry in terminally differentiated ventricular myocytes. Adult rat ventricular myocytes were analyzed 72 h after infection with recombinant adenovirus encoding E2F-1, Bcl-2, or both, versus virus containing the CMV transcriptional control region but no cDNA. $(A-D)$ Nuclear fragmentation indicative of apoptosis was induced by E2F-1 and largely prevented by Bcl-2, shown using the bisbenzimide dye, Hoechst 33258. (E-L) Apoptosis was induced by E2F-1 and alleviated by Bcl-2, as corroborated by the nick end-labeling method; $E-H$ (phase-contrast) and $I-L$ (epifluorescence microscopy) correspond to identical fields, whereas the others do not. ( $M-P$ ) DNA synthesis was induced by E2F-1, assessed as BrdU incorporation, using FITC-conjugated antibody to BrdU and indirect immunostaining for sarcomeric myosin heavy chains. $(A, E, I$, and $M)$ Control virus; $(B, F, J$, and $N) \mathrm{E} 2 \mathrm{~F}-1 ;(C, G, K$, and $O) \mathrm{Bcl}-2 ;(D, H, L$, and $P) \mathrm{E} 2 \mathrm{~F}-1+\mathrm{Bcl}-2$. $(Q) \mathrm{Sum}-$ mary of the E2F-1 and Bcl-2 effects on apoptosis and DNA synthesis (mean \pm SEM). $(R)$ Western blot analysis for E2F-1, potential target genes, and sarcomeric $\alpha$-actin. Human 293 cells are included, at the left, for comparison.

overrides the block to DNA synthesis in G2/M. We have not examined later time points systematically, given the risk that adult cardiac myocytes dedifferentiate over more extended periods in cell culture, which can itself affect the susceptibility to cell cycle reentry (24). Thus, we do not exclude the possibility that Bcl-2 delays rather than prevents E2F-1-dependent apoptosis.

To test whether the G1 checkpoint could also be overcome by E2F-1 in adult myocardium, apical injections were performed, under direct visualization after thoracotomy (15) (Fig. 2). Expression and nuclear localization of E2F-1 first were confirmed by indirect immunohistochemistry (Fig. 2, $A$ and $B) .3 \mathrm{~d}$ after infection with E2F-1, BrdU incorporation was detected in ventricular myocytes and nonmuscle cells of both p53-deficient and wild-type animals (Fig. 2, $C$ and $E$ ). BrdU incorporation was not detected either in the uninjected left ventricular free wall of hearts receiving E2F-1 (Fig. 2D), or in myocardium receiving the control virus encoding nls-LacZ (Fig. $2 \mathrm{~F}$ ). To rule out fortuitous disparities in the efficacy of virus uptake or expression, both p53 genotypes were compared after injection of virus encoding nls-LacZ: no significant difference was seen between strains in the prevalence of adenoviral transduction (Fig. 2, $G$ and $H$ ). To confirm a bona fide increase in DNA content and to test for completion of $S$ phase, sections were analyzed by Feulgen cytophotometry (10) (Fig. 2, I and $J)$. In uninjected regions of both strains, or in regions injected with the control virus encoding nls-LacZ, a single G0/G1 peak predominated. Under these two control conditions, virtually 

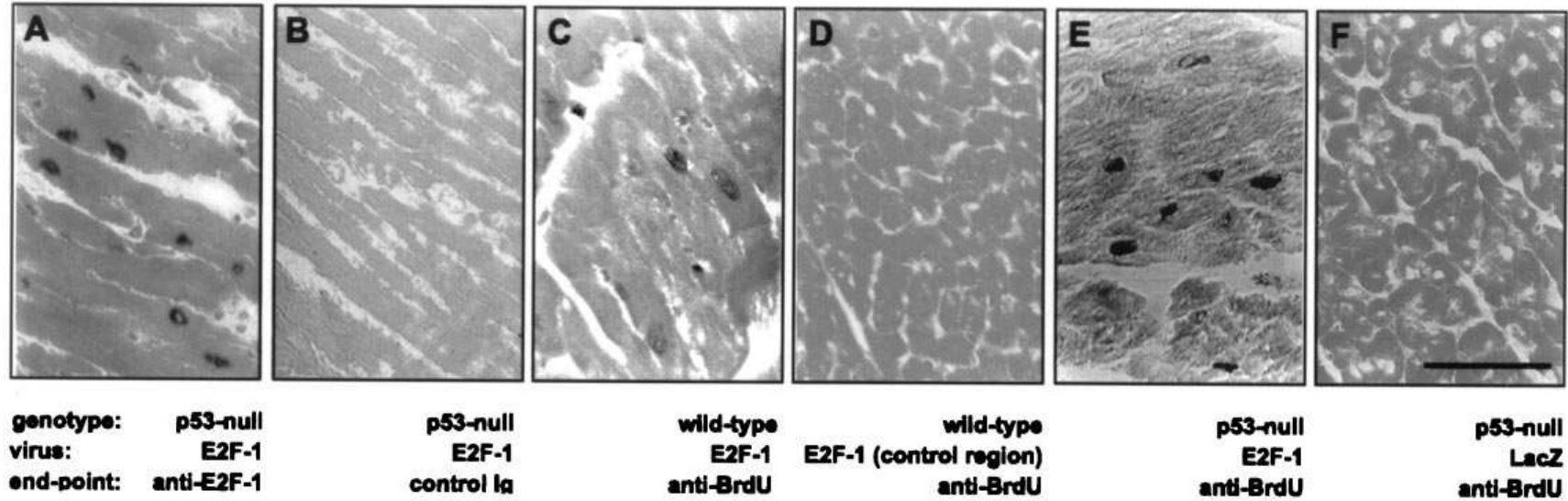

end-point: anti-E2F-1

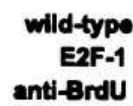

wild-type

E2F-1 (control region)

ant-BrdU

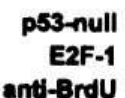

p53-null

Lacz

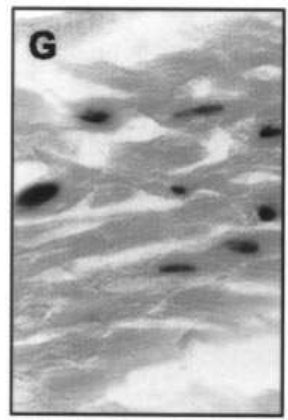

genotype: wild-type virus: end-point:

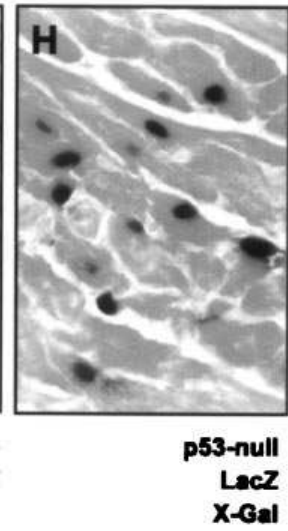

\section{I}
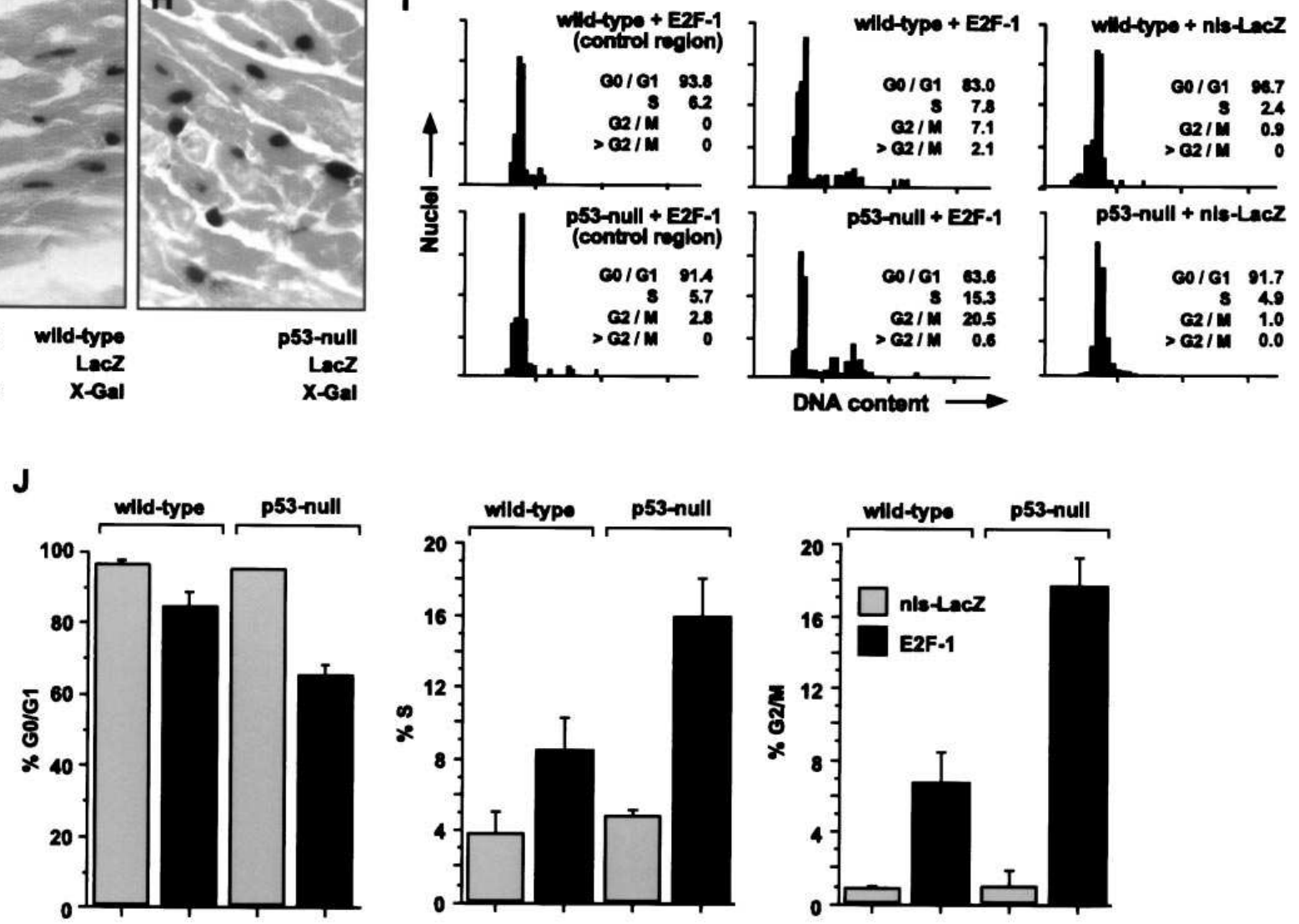

Figure 2. Endogenous p53 inhibits the action of E2F-1 in adult myocardium in vivo. ( $A$ and $B)$ E2F-1 expression and intracellular targeting in vivo first were tested $4 \mathrm{~d}$ after intramyocardial injection using p53-deficient mice, which were postulated to comprise a more permissive environment for cell cycle reentry. $(A)$ Nuclear localization of E2F-1, after injection of adenovirus containing CMV-driven E2F-1; $(B)$ absence of factitious staining, using mouse IgG as the irrelevant primary antibody. $(C-J)$ Wild-type and p53-deficient mice inoculated with adenovirus containing CMV-driven E2F-1 versus CMV-driven nls-LacZ were analyzed $3 \mathrm{~d}$ after injection, by immunostaining for $\mathrm{BrdU}(C-F), \mathrm{X}$-gal staining $(G$ and $H$ ), and image analysis of Feulgen-stained nuclei $(I$ and $J)$. Cell cycle reentry was induced by exogenous E2F-1 in both genetic backgrounds; however, the prevalence of G1 exit (substantiated as DNA content per nucleus) and of accumulation in G2/M was threefold higher in p53-null mice ( $10 \%$ in wild-type vs. $30 \%$ in p53-null mice). Bar, $50 \mu \mathrm{m}$. The DNA histograms $(I)$ indicate $\sim 100$ nuclei from a single mouse for each condition shown, and are representative of two to three independent injections. Mean results are shown in $J$.

no nuclei were detected in $\mathrm{G} 2 / \mathrm{M}$ in either genetic background, and the absence of p53 had no significant effect on G1 exit (96 vs. $94 \%$ in G0/G1, in wild-type vs. p53-null mice). By contrast, in wild-type mice, E2F-1 caused G1 exit in $15 \%$ of nuclei $\left(\chi^{2}=\right.$ 17.6, $P<0.0001$, vs. nls-LacZ), with $7 \%$ in $\mathrm{G} 2 / \mathrm{M}$. In $\mathrm{p} 53^{-/-}$ mice, this was increased more than twofold, to $34 \%\left(\chi^{2}=89.5\right.$, $P<0.0001$, vs. nls-LacZ; $\chi^{2}=37.6, P<0.0001$, vs. wild-type mice injected with E2F-1); $17 \%$ of nuclei were in G2/M. No mitotic figures were detected.

The apparent augmentation of G1 exit triggered by E2F-1 

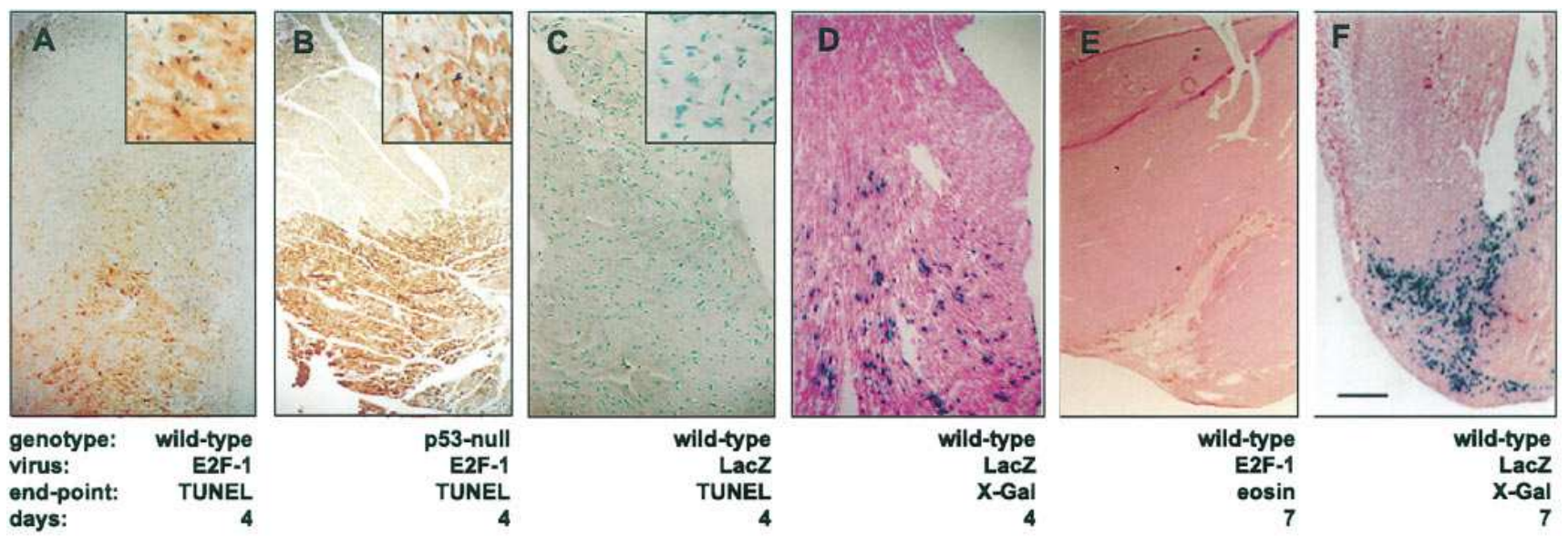

G

H
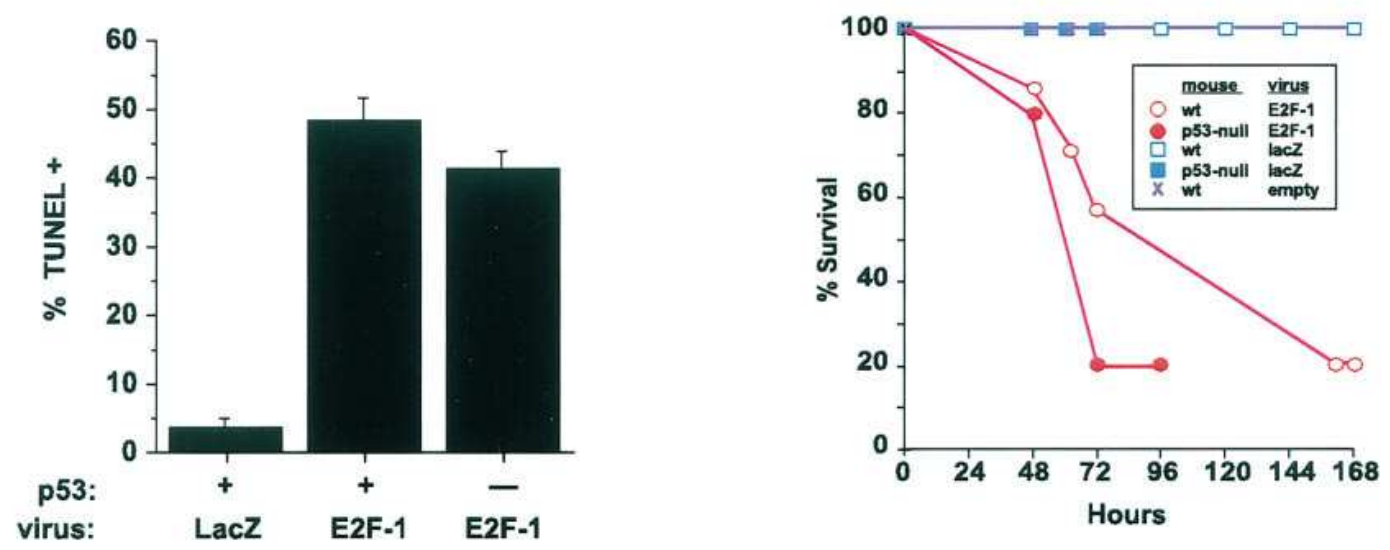

Figure 3. E2F-1 provokes apoptosis in adult myocardium and rapid mortality, through a p53-independent pathway. Wild-type and p53-deficient mice inoculated with adenovirus containing CMV-driven E2F-1 versus CMV-driven nls-LacZ were analyzed by the in situ TUNEL technique $(A-C$ and $G)$ and $\mathrm{X}$-gal staining $(D$ and $F)$. Apoptosis was specific to the injected region of myocardium and was not evoked by the control virus encoding LacZ $(A-D)$. Marked myocyte loss at the site of injection with E2F-1 is apparent at $7 \mathrm{~d}(E)$, but did not result from intramyocardial injection of the control virus $(F)$. The apical region of injection appears at the bottom of each long-axis section shown in $A-F$. The calibration bar in $F$ denotes $500 \mu \mathrm{m}$ for each panel, and $100 \mu \mathrm{m}$ for the insets. $(H)$ E2F-1-induced mortality after intramyocardial injection also was independent of $\mathrm{p} 53$.

in p53-deficient mice could in principle result from effects on cycling per se, or on differences in the survival of successfully infected cells. To explore whether the p53 effect might occur through apoptosis, in situ nick end-labeling was performed (Fig. 3, $A-D$ and $G$ ). $3 \mathrm{~d}$ after injection, the prevalence of TUNEL-positive nuclei was $<1 \%$ in the uninjected control regions (left ventricular free wall) for both strains receiving E2F-1, and 3\% for injected regions of wild-type mice receiving nls-LacZ. By contrast, apoptosis increased to $46 \%$ in the injected regions of wild-type mice receiving E2F-1 $\left(x^{2}=76.5, P<\right.$ 0.0001 , vs. nls-LacZ), and was not significantly affected by the absence of p53 (40\%). Consequently, apoptosis induced by E2F-1 in postmitotic myocardium is largely p53-independent. Furthermore, rapid mortality also resulted in both strains, within $5 \mathrm{~d}$ after injection of E2F-1 (Fig. $3 \mathrm{H}$ ). Scarring and myocyte loss were evident in apical myocardium $7 \mathrm{~d}$ after injection with E2F-1, but not with nls-LacZ (Fig. 3, $E$ and $F$ ).

\section{Discussion}

To our knowledge, the finding that E2F-1 suffices for reactivation and completion of DNA synthesis in postmitotic cardiac muscle in vivo is the first demonstration that cell cycle reentry can be triggered de novo in the adult heart by any exogenous gene, and-despite evidence for $\mathrm{E} 2 \mathrm{~F}$ as sufficient for $\mathrm{S}$ phase elsewhere (19) - the first indication that E2F-1 can override this constraint in postmitotic mammalian cells. Thus, this investigation complements work on E2F in cardiac (10) and skeletal myocytes $(25,26)$ before irreversible exit from the cell cycle. By contrast, some cell types are refractory to E2F-1, despite responsiveness to TAg (27). Notably, among these, postmitotic skeletal myocytes are reportedly susceptible to cell cycle reentry induced by TAg $(28,29)$ or E1A $(30)$, but not by E2F-1 (31). This discrepancy may be explained by host cell proteins bound by TAg and E1A apart from pocket proteins, 
including p300 (32-34), or by differences in control of endogenous cell cycle regulators. For example, upregulation of endogenous cardiac cell cycle proteins, including Cdk4 but not $\mathrm{Cdc} 2$, was noted in transgenic mice with cyclin D1 targeted to myocardium (35), overlapping only partially the response to exogenous E2F-1. In this context, it is noteworthy that angiotensin II and FBS both reportedly cause hyperphosphorylation of $\mathrm{Rb}$ in neonatal rat cardiac myocytes, under conditions that do not lead to DNA synthesis (36): it is unknown whether free E2F was increased, as would be predicted, whether differences in endogenous E2F itself versus other proteins account for this uncoupling, or whether E2F, in such circumstances, plays a functional role in hypertrophic growth.

While the long-term potential for therapeutic interventions aimed at the cardiac cell cycle is encouraged by our report, several obstacles are readily apparent. S phase entry was accompanied by widespread apoptosis, indicating a need for Bcl-2 or alternative antiapoptotic genes. Successful coinfection of cardiac myocytes by two adenoviruses is achievable in vivo (15), but the uncertain prevalence for coinfection suggests that this would be better addressed using tandem expression cassettes, or, for murine studies, by overexpressing Bcl-2 in myocardium. Moreover, E2F-1 expression or function would presumably need to be reversible. Given the extensive myocyte loss and precipitous death induced by E2F-1, arrhythmogenic foci are a likely explanation for mortality here, but systemic effects cannot be ruled out; a useful refinement would be delivery using a cardiac-specific promoter. Whereas forced expression of wild-type p53 can be sufficient for apoptosis in cardiac myocytes $(37,38)$, p53-independent mechanisms have been noted as a cause for apoptosis in other cell types, such as during G2/M (39), or in Rb-deficient cells (40) and animals (41). The higher prevalence for apoptosis than for BrdU synthesis, after in vitro infection with E2F-1, may appear confusing. Highlighted by a very recent report (42), apoptosis and cell cycle reentry induced by E2F proteins are neither mutually dependent nor obligatorily linked: E2F-2 and E2F-3 can reactivate the cell cycle without triggering cell death, although this property has not yet been tested in adult cardiac muscle or other postmitotic cells. This conclusion, that apoptosis and cell cycling are independent effects of E2F, also draws support from the mutagenesis of E2F-1 itself (40). Consequently, adult ventricular myocytes might be more susceptible to the apoptotic pathway induced by E2F-1 than to G1 exit, under these experimental conditions. Alternatively, apoptosis might merely precede DNA synthesis. Furthermore, in the absence of exogenous Bcl-2, the loss of some BrdU-positive cells is likely by the 72-h time point shown, after infection with E2F-1 alone. However, BrdU-positive myocytes were never seen 24 or $48 \mathrm{~h}$ after infection.

More fundamentally, we observed a more than twofold increase in the proportion of cells entering and completing $\mathrm{S}$ phase after delivery of E2F-1 to p53-null mice, as demonstrated by accumulation of cells in G2/M. This supports a cooperative role for $\mathrm{p} 53$ and pocket proteins in maintaining cell quiescence in adult myocardium. The failure to progress beyond this $\mathrm{G} 2 / \mathrm{M}$ checkpoint is noteworthy. With the ability to trigger de novo cell cycle reentry, viral delivery of E2F-1 complements related studies of the postmitotic cardiac phenotype in transgenic mice that overexpress cyclin D1 (35). Notably, both approaches have identified a corresponding need for interventions focused on genes controlling the G2/M boundary as a further target to promote cell cycle reentry in the adult heart.

\section{Acknowledgments}

We thank F. Graham, J. Nevins, and B. French for reagents cited; F. Ervin, R. Geske, D. de Moissac, C. Miller, P. Jackson, and J. Parker for assistance, T. Brand for comments, and R. Roberts for encouragement and support.

This work was supported in part by National Institutes of Health grants (R01 HL-47567, R01 HL-52555, P01 HL-49953, and P50 HL42267) to M.D. Schneider, and by the Medical Research Council of Canada to L.A. Kirshenbaum. L.A. Kirshenbaum is a Scholar of the Heart and Stroke Foundation of Canada.

\section{References}

1. Weinberg, R.A. 1995. The retinoblastoma protein and cell cycle control. Cell. 81:323-330.

2. Harper, J.W., and S.J. Elledge. 1996. Cdk inhibitors in development and cancer. Curr. Opin. Genet. Dev. 6:56-64.

3. Weinberg, R.A. 1996. E2F and cell proliferation: a world turned upside down. Cell. 85:457-459.

4. Yang, Z.Y., R.D. Simari, N.D. Perkins, H. San, D. Gordon, G.J. Nabel, and E.G. Nabel. 1996. Role of the p21 cyclin-dependent kinase inhibitor in limiting intimal cell proliferation in response to arterial injury. Proc. Natl. Acad. Sci. USA. 93:7905-7910.

5. Chang, M.W., E. Barr, J. Seltzer, Y.Q. Jiang, G.J. Nabel, E.G. Nabel, M.S. Parmacek, and J.M. Leiden. 1995. Cytostatic gene therapy for vascular proliferative disorders with a constitutively active form of the retinoblastoma gene product. Science. 267:518-522.

6. Morishita, R., G.H. Gibbons, M. Horiuchi, K.E. Ellison, M. Nakajima, L. Zhang, Y. Kaneda, T. Ogihara, and V.J. Dzau. 1995. A gene therapy strategy using a transcription factor decoy of the E2F binding site inhibits smooth muscle proliferation in vivo. Proc. Natl. Acad. Sci. USA. 92:5855-5859.

7. Soonpaa, M.H., G.Y. Koh, M.G. Klug, and L.J. Field. 1994. Formation of nascent intercalated disks between grafted fetal cardiomyocytes and host myocardium. Science. 264:98-101.

8. Kirshenbaum, L.A., and M.D. Schneider. 1995. Adenovirus E1A represses cardiac gene transcription and reactivates DNA synthesis in ventricular myocytes, via alternative pocket protein- and p300-binding domains. J. Biol. Chem. 270:7791-7794.

9. Raychaudhuri, P., S. Bagchi, S.H. Devoto, V.B. Kraus, E. Moran, and J.R. Nevins. 1991. Domains of the adenovirus E1A protein required for oncogenic activity are also required for dissociation of E2F transcription factor complexes. Genes Dev. 5:1200-1211.

10. Kirshenbaum, L.A., M. Abdellatif, S. Chakraborty, and M.D. Schneider. 1996. Human E2F-1 reactivates cell cycle progression in ventricular myocytes and represses cardiac gene transcription. Dev. Biol. 179:402-411.

11. Schneider, J.W., W. Gu, L. Zhu, V. Mahdavi, and B. Nadal-Ginard. 1994. Reversal of terminal differentiation mediated by p107 in $\mathrm{Rb}(-/-)$ muscle cells. Science. 264:1467-1471.

12. Kowalik, T.F., J. Degregori, J.K. Schwarz, and J.R. Nevins. 1995. E2F1 overexpression in quiescent fibroblasts leads to induction of cellular DNA synthesis and apoptosis. J. Virol. 69:2491-2500.

13. Donehower, L.A., M. Harvey, B.L. Slagle, M.J. McArthur, C.A. Montgomery, J.S. Butel, and A. Bradley. 1992. Mice deficient for p53 are developmentally normal but susceptible to spontaneous tumours. Nature. 356:215-221.

14. Subramanian, T., B. Tarodi, and G. Chinnadurai. 1995. p53-independent apoptotic and necrotic cell deaths induced by adenovirus infection: suppression by E1B $19 \mathrm{~K}$ and Bcl-2 proteins. Cell Growth Differ. 6:131-137.

15. Agah, R., P.A. Frenkel, B.A. French, L.H. Michael, P.A. Overbeek, and M.D. Schneider. 1997. Gene recombination in postmitotic cells. Targeted expression of Cre recombinase provokes cardiac-restricted, site-specific rearrangement in adult ventricular muscle in vivo. J. Clin. Invest. 100:169-179.

16. Kirshenbaum, L.A., W.R. MacLellan, W. Mazur, B.A. French, and M.D. Schneider. 1993. Highly efficient gene transfer to adult rat ventricular myocytes by recombinant adenovirus. J. Clin. Invest. 92:381-387.

17. Bugaisky, L.B., and R. Zak. 1989. Differentiation of adult rat cardiac myocytes in cell culture. Circ. Res. 64:493-500.

18. Eppenberger-Eberhard, T.M., I. Flamme, V. Kurer, and H.M. Eppenberger. 1990. Re-expression of alpha-smooth muscle actin isoform in cultured adult rat cardiomyocytes. Dev. Biol. 139:269-278.

19. Degregori, J., T. Kowalik, and J.R. Nevins. 1995. Cellular targets for activation by the E2F1 transcription factor include DNA synthesis- and G1/S-regulatory genes. Mol. Cell. Biol. 15:4215-4224.

20. Soonpaa, M.H., K.K. Kim, L. Pajak, M. Franklin, and L.J. Field. 1996. Cardiomyocyte DNA synthesis and binucleation during murine development. Am. J. Physiol. 271:H2183-H2189.

21. Soonpaa, M.H., G.Y. Koh, L. Pajak, S.L. Jing, H. Wang, M.T. Franklin, K.K. Kim, and L.J. Field. 1997. Cyclin D1 overexpression promotes cardiomyocyte DNA synthesis and multinucleation in transgenic mice. J. Clin. Invest. 99: 
2644-2654.

22. Deng, G., and E.R. Podack. 1993. Suppression of apoptosis in a cytotoxic T-cell line by interleukin 2-mediated gene transcription and deregulated expression of the protooncogene bcl-2. Proc. Natl. Acad. Sci. USA. 90:21892193.

23. Walker, A., S.T. Taylor, J.A. Hickman, and C. Dive. 1997. Germinal center-derived signals act with Bcl-2 to decrease apoptosis and increase clonogenicity of drug-treated human B lymphoma cells. Cancer Res. 57:1939-1945.

24. Claycomb, W.C., and R.L. Moses. 1988. Growth factors and TPA stimulate DNA synthesis and alter the morphology of cultured terminally differentiated adult rat cardiac muscle cells. Dev. Biol. 127:257-265.

25. Wang, J., K. Helin, P. Jin, and B. Nadal-Ginard. 1995. Inhibition of in vitro myogenic differentiation by cellular transcription factor E2F1. Cell Growth Differ. 6:1299-1306.

26. Guo, K., and K. Walsh. 1997. Inhibition of myogenesis by multiple cyclin-Cdk complexes. Coordinate regulation of myogenesis and cell cycle activity at the level of E2F. J. Biol. Chem. 272:791-797.

27. Chandrasekaran, C., C.M. Coopersmith, and J.I. Gordon. 1996. Use of normal and transgenic mice to examine the relationship between terminal differentiation of intestinal epithelial cells and accumulation of their cell cycle regulators. J. Biol. Chem. 271:28414-28421.

28. Ohkubo, Y., T. Kishimoto, T. Nakata, H. Yasuda, and T. Endo. 1994. SV40 large $\mathrm{T}$ antigen reinduces the cell cycle in terminally differentiated myotubes through inducing cdk2, cdc2, and their partner cyclins. Exp. Cell Res. 214: $270-278$

29. Wang, J., and B. Nadal-Ginard. 1995. Regulation of cyclins and p34CDC2 expression during terminal differentiation of $\mathrm{C} 3 \mathrm{C} 12$ myocytes. Biochem. Biophys. Res. Commun. 206:82-88.

30. Tiainen, M., D. Spitkovsky, P. Jansen-Durr, A. Sacchi, and M. Crescenzi. 1996. Expression of E1A in terminally differentiated muscle cells reactivates the cell cycle and suppresses tissue-specific genes by separable mechanisms. Mol. Cell. Biol. 16:5302-5312.

31. Tiainen, M., D. Pajalunga, F. Ferrantelli, S. Soddu, G. Salvatori, A. Sacchi, and M. Crescenzi. 1996. Terminally differentiated skeletal myotubes are not confined to G0 but can enter G1 upon growth factor stimulation. Cell Growth Differ. 7:1039-1050.

32. Eckner, R., M.E. Ewen, D. Newsome, M. Gerdes, J.A. Decaprio, J.B. Lawrence, and D.M. Livingston. 1994. Molecular cloning and functional analysis of the adenovirus E1A-associated $300-\mathrm{kD}$ protein (p300) reveals a protein with properties of a transcriptional adaptor. Genes Dev. 8:869-884.

33. Eckner, R., J.W. Ludlow, N.L. Lill, E. Oldread, Z. Arany, N. Modjtahedi, J.A. Decaprio, D.M. Livingston, and J.A. Morgan. 1996. Association of p300 and CBP with simian virus 40 large T antigen. Mol. Cell. Biol. 16:34543464.

34. Avantaggiati, M.L., M. Carbone, A. Graessmann, Y. Nakatani, B. Howard, and A.S. Levine. 1996. The SV40 large T antigen and adenovirus E1a oncoproteins interact with distinct isoforms of the transcriptional co-activator, p300. EMBO (Eur. Mol. Biol. Organ.) J. 15:2236-2248.

35. Soonpaa, M.H., G.Y. Koh, L. Pajak, S. Jing, H. Wang, M.T. Franklin, K.K. Kim, and L.J. Field. 1997. Cyclin D1 overexpression promotes cardiomyocyte DNA synthesis and multinucleation in transgenic mice. J. Clin. Invest. 99: 2644-2654.

36. Sadoshima, J., H. Aoki, and S. Izumo. 1997. Angiotensin II and serum differentially regulate expression of cyclins, activity of cyclin-dependent kinases, and phosphorylation of retinoblastoma gene product in neonatal cardiac myocytes. Circ. Res. 80:228-241.

37. Long, X., M.O. Boluyt, M. Hipolito, M.S. Lundberg, J-S. Zheng, L. O'Neill, C. Cirielli, E.G. Lakatta, and M.T. Crow. 1997. p53 and the hypoxiainduced apoptosis of cultured neonatal rat cardiac myocytes. J. Clin. Invest. 99: 2635-2643.

38. Kirshenbaum, L.A., and D. de Moissac. 1997. The bcl-2 gene product prevents programmed cell death of ventricular myocytes. Circulation. 96:15801585

39. Allday, M.J., G.J. Inman, D.H. Crawford, and P.J. Farrell. 1995. DNA damage in human B cells can induce apoptosis, proceeding from G1/S when p53 is transactivation competent and $\mathrm{G} 2 / \mathrm{M}$ when it is transactivation defective. EMBO (Eur. Mol. Biol. Organ.) J. 14:4994-5005.

40. Hsieh, J.K., S. Fredersdorf, T. Kouzarides, K. Martin, and X. Lu. 1997. E2F1-induced apoptosis requires DNA binding but not transactivation and is inhibited by the retinoblastoma protein through direct interaction. Genes Dev. 11:1840-1852.

41. Macleod, K.F., Y.W. Hu, and T. Jacks. 1996. Loss of Rb activates both p52-dependent and independent cell death pathways in the developing mouse nervous system. EMBO (Eur. Mol. Biol. Organ.) J. 15:6178-6188.

42. DeGregori, J., G. Leone, A. Miron, L. Jakoi, and J.R. Nevins. 1997. Distinct roles for E2F proteins in cell growth control and apoptosis. Proc. Natl. Acad. Sci. USA. 94:7245-7250. 